\title{
Species and size diversity in protective services offered by coral guard-crabs
}

Coral guard-crabs in the genus Trapezia are well-documented defenders of their pocilloporid coral hosts against coral predators such as the Crown-of-Thorns seastar (Acanthaster planci complex). The objectives of this study were to examine the protective services of six species of Trapezia against corallivory, and the extent of functional diversity among these Trapezia species.

Studies conducted in Mo'orea, French Polynesia showed the Trapezia - coral mutualism protected the host corals from multiple predators through functional diversity in the assemblage of crab symbionts. Species differed in their defensive efficacy, but species within similar size classes shared similar abilities. Smaller-size Trapezia species, which were previously thought to be ineffective guards, play important defensive roles against small corallivores.

We also measured the benefits of this mutualism to corals in the midst of an Acanthaster outbreak that reduced the live coral cover on the fore reef to less than $4 \%$. The mutualism may positively affect the reef coral demography and potential for recovery during adverse predation events through shelter of multiple species of small corals near the host coral. Our results show that while functional diversity is supported within the genus, some Trapezia species may be functionally equivalent within the same size class, decreasing the threat of gaps in coral protection caused by absence or replacement of any single Trapezia species. 


\section{Species and size diversity in protective services offered by coral guard-crabs}

\section{C. Seabird $M^{c} K^{2}{ }^{1,2,3}$ and Jenna M. Moore ${ }^{1}$}

$4 \quad{ }^{1}$ Florida Museum of Natural History, University of Florida, Gainesville, FL USA

$5{ }^{2}$ Smithsonian Institution Marine Science Network, Smithsonian Marine Station, Fort Pierce, FL USA

6 mckeons@si.edu

$7 \quad{ }^{3}$ Corresponding Author 
9 Coral guard-crabs in the genus Trapezia are well-documented defenders of their

10 pocilloporid coral hosts against coral predators such as the Crown-of-Thorns seastar (Acanthaster

11 planci complex). The objectives of this study were to examine the protective services of six

12 species of Trapezia against corallivory, and the extent of functional diversity among these

13 Trapezia species.

14 Studies conducted in Mo'orea, French Polynesia showed the Trapezia - coral mutualism

15 protected the host corals from multiple predators through functional diversity in the assemblage

16 of crab symbionts. Species differed in their defensive efficacy, but species within similar size

17 classes shared similar abilities. Smaller-size Trapezia species, which were previously thought to

18 be ineffective guards, play important defensive roles against small corallivores.

19 We also measured the benefits of this mutualism to corals in the midst of an Acanthaster

20 outbreak that reduced the live coral cover on the fore reef to less than $4 \%$. The mutualism may

21 positively affect the reef coral demography and potential for recovery during adverse predation

22 events through shelter of multiple species of small corals near the host coral. Our results show

23 that while functional diversity is supported within the genus, some Trapezia species may be

24 functionally equivalent within the same size class, decreasing the threat of gaps in coral

25 protection caused by absence or replacement of any single Trapezia species.

26 Key Words: Functional Diversity, Functional Equivalence, Mutualism, Trapezia, Pocillopora,

27 Acanthaster, Associational Refuge, Complementarity, Symbiosis, Partner Benefits

\section{Introduction}



antagonism between host and symbiont, eliminating "arms races" that could result in extinction;

2) increasing the resistance of each species to stressors external to the relationship; and 3) enhancing survival benefits for many species in complementary assemblages of mutualists and mutualistic networks. Mutualisms often occur with more than one species providing benefits to a host species, and community diversity within symbiotic suites has been largely overlooked (Howe 1984). High mutualist diversity may confer greater survival benefits to the host species than a single mutualist (Stachowicz and Whitlatch 2005; Baskett et al. 2009), especially if

37 functional diversity exists in the system. Whole communities may have net beneficial effects for 38 a shared host that can be considered mutualistic in nature (Bracken et al. 2007; Stachowicz et al.

39 2008). Studies on the interactions between mutualist species are underrepresented in the

40 literature (Morris et al. 2007), but relevant and central to understanding diverse systems ( $\mathrm{M}^{\mathrm{c}} \mathrm{Keon}$

41 et al. 2012). Mutualist diversity within symbiotic suites drives variation in partner benefits,

42 strongly impacting the extent and strength of these ecological partnerships (Schemske and

43 Horvitz 1984; Addicott 1986; Meunier et al. 1999; Correa and Baker 2009).

Functional diversity and equivalence in ecological roles of similar species have become

45 focal points in our understanding of community structure and the generation and maintenance of

46 biodiversity (Harris 1995; Loreau et al. 2002; Loreau 2004). Diversity has been simplified into

47 ecological units of 'functional groups', but studies testing the equivalence of species within

48 functional groups have shown mixed results (Chalcraft and Resetarits 2003). The few studies to

49 date comparing ecological function of closely related species under the same environmental

50 conditions have supported the idea that functional diversity, rather than equivalence, may be the

51 norm (Resetarits and Chalcraft 2007). Despite this evidence, the assumptions of functional

52 equivalence underlying the construction of functional groups have remained a central premise in 
53 much of theoretical ecology, from Neutral Theory (Hubbell 2005) to Food Web Theory (Menge

54 and Sutherland 1987; Leibold and McPeek 2006).

55 Testing for functional diversity and equivalence is most tractable and applicable in clades

56 of closely related or morphologically similar species (Leibold and McPeek 2006). Crabs of the

57 genus Trapezia differ in size but exhibit few other morphological differences. Trapezia are

58 defensive mutualists of coral hosts in the family Pocilloporidae (Pearson and Endean 1969;

59 Glynn 1976, 1987). These crabs have been implicated in providing a number of ecological

60 services to their host corals: repulsion of corallivores (Glynn 1987; Pratchett 2001), removal of

61 sediment (Stewart et al. 2006), and alleviation of the impacts of vermetid snails (Stier et al.

62 2010). The functional differences between different species of this well-known marine mutualist

63 genus have not yet been examined in detail.

64 Trapezia are part of an assemblage of specialized associates of pocilloporid corals.

65 Pocillopora make up a large percentage of reef cover in lagoonal and fore reef systems in the

66 Indo-Pacific. Fourteen of the 22 described Trapezia species occur in French Polynesia (Castro

67 1997). Symbiont community composition varies with coral species, growth form, reef zone, and

68 community membership (Odinetz 1983). The maximum size of Trapezia is constrained by host

69 interbranch width (Adams et al. 1985; Huber and Coles 1985). A single mating pair of a given

70 Trapezia species typically occupies each coral colony, although each colony can host multiple

71 species and additional juveniles. Larger coral colonies may host pairs of up to five species of

72 Trapezia, while smaller coral colonies may only shelter a single species. The benefits to the

73 Trapezia include shelter and nutrition in the form of lipids sequestered in the tips of the polyp

74 tentacles, which the crabs graze (Stimson 1990).

75 The objectives of this study were: 1) to evaluate the services of multiple Trapezia species

76 to their host corals; 2) to make interspecific comparisons of functional roles in Trapezia; and 3) to

77 assess the effect of symbiont size on functional role. We compared the defensive efficacy of 
78 several species and size classes of Trapezia against two corallivores in lab experiments. We also

79 examined the role of the Pocillopora-Trapezia mutualism in mitigating the effects of

80 Acanthaster planci, the Crown-of-Thorns sea star, during a natural outbreak event.

\section{Methods}

82 Study Locations

83 Corallivore defense studies were conducted in Mo'orea, French Polynesia, at the Richard

84 B. Gump Research Station of the University of California, utilizing the flow-through seawater 85 system and a fore reef field site.

86 Study Organisms

Pocillopora species make up a large percentage of reef cover in lagoonal and fore reef systems in the Indo-Pacific. The bulk of this is composed of coral colonies with morphologies in three coarse groupings. The Pocillopora verrucosa - P. meandrina group, referred to in this manuscript as "Pocillopora verrucosa", are mid-sized pocilloporids, rarely exceeding $15 \mathrm{~cm}$ in

91 colony height and typically occupied by small- to medium-sized Trapezia species. A second 92 morphological group, the P. eydouxi-P. woodjonesi group (hereafter "Pocillopora eydouxi"), is

93 larger in stature, commonly exceeding $60 \mathrm{~cm}$ in colony height, and has substantially broader 94 interbranch widths. These corals host the entire size range of Trapezia species; from the smallest 95 at branch junctures and the colony's base, to the largest, which actively transit the openings

96 between branches. The third morphological grouping is composed of species currently assigned

97 to Pocillopora damicornis, a finely branched morphotype that exhibits extreme environmental

98 variation across reef microhabitats (Veron and Pichon 1976).

99 Species-level distinctions across the geographic range of Pocillopora remain unresolved

100 at morphological, genetic, and taxonomic levels (Veron and Pichon 1976, Veron 2000, Combosch

101 et al. 2008). As such, we chose to use internally consistent morphological groupings in the

102 experiments, but do not have further identification of the entities involved. 
104 Acanthaster "planci" (Linnaeus 1758), a species complex (Vogler et al. 2008); the seastar

105 Culcita novaeguineae Müller \& Troschel 1842; and the muricid gastropod Drupella cornus

106 (Röding 1798). For simplicity, we will refer to these species by their generic name only hereafter.

107 These species are the most common coral predators on Indo-Pacific reefs. Acanthaster

108 often occurs in high densities during population booms (Birkeland 1989). Acanthaster is capable

109 of consuming all reef corals, but does exhibit feeding preferences (Pratchett 2007; Pratchett et al.

110 2009). Culcita is a generalist predator of sessile organisms, including corals (Glynn and Krupp

111 1986). Drupella is a specialized corallivore whose impact on reef corals is second only to

112 Acanthaster (Turner 1994). The three species feed on corals nocturnally, and leave visible 'scars'

113 of exposed coral skeleton in the course of a single feeding event.

114 Experiments on defense utilized single reproductive pairs of Trapezia punctimanus

115 Odinetz 1984 (a species of generally smaller size within the study area); T. bidentata (Forskål,

116 1775) and T. serenei Odinetz, 1984 (medium sized species); and T. flavopunctata Eydoux \&

117 Souleyet, 1842 (a large species). Small carapace-width (CW) pairs of T. serenei were also used

118 as a 'small' species in the experiments with Drupella, as crabs of this species reach sexual

119 maturity at much smaller sizes when living within small coral colonies. The first author

120 identified the crabs to species, relying on Castro et al. (2004), the original species descriptions,

121 and molecular data ( $\mathrm{M}^{\mathrm{c}}$ Keon 2010) from voucher specimens deposited at the Florida Museum of

122 Natural History.

123 Experimental Design

$124 \quad$ Four species of Trapezia were used in experiments evaluating defense against the three

125 corallivores. These were: T. serenei Odinetz 1984 (two size classes: small 4-6 mm CW, and

126 medium 9-11 mm CW), T. punctimanus Odinetz 1984 (small size class: 4-6 mm CW), $T$.

127 bidentata (Forskål 1775); (medium size class: 9-11 mm CW), and T. flavopunctata Eydoux \& 
128 Souleyet 1842 (large size class: $>11 \mathrm{~mm} \mathrm{CW}$ ). The differences in size between the three species

129 of corallivore (Acanthaster planci [a large predatory asteroid], Culcita novaeguineae [a medium

130 sized asteroid predator], and Drupella cornus [a small predatory snail]) allowed for evaluation of

131 the impact of size of both predator and defender in the defensive efficacy of species of Trapezia.

132 The extreme difference in size among corallivore, coral host, and crabs necessitated different

133 experimental approaches to assess the range of defensive behaviors. Large individuals of

134 Acanthaster in particular were unreliable predators in lab feeding trials, but were easy to track

135 during field experiments, while Culcita and Drupella would readily attempt feeding during a

136 single night in the lab chambers, but were difficult to trace in the field.

137

During 2008 and 2009, Mo'orea experienced an outbreak of Acanthaster, allowing field

138 manipulations to test the effect of Trapezia defense on Acanthaster predation. By September

139 2008, the majority of live coral had been eaten, with the notable exception of Pocillopora

140 eydouxi Milne Edwards \& Haime 1860, which occurs on the forereef and hosts pairs of $T$.

141 flavopunctata as well as a suite of other symbiotic species. A closely related species, Pocillopora

142 damicornis Linnaeus, 1758 is a highly favored food in the diet of Acanthaster (Pratchett 2007).

143 Smaller Pocillopora verrucosa (Ellis \& Solander 1786) had been consumed in near totality, and

144 least-favored taxa such as Porites and soft corals were also being eaten.

145 Drupella cornus

146 Two sets of experiments tested the defensive efficacy of two size classes of Trapezia

147 serenei (small adult crabs 4-6 mm CW, and medium adult crabs 9-10 $\mathrm{mm} \mathrm{CW}$ ) and one size class

148 of T. punctimanus (small - 4-6 mm CW) against the corallivorous snail Drupella cornus. Two

$149135 \mathrm{~L}$ aquaria equipped with flowing seawater served as experimental chambers. Pocillopora

150 verrucosa colonies were gathered from the back reef environment on the day of the experiments.

151 Small coral colonies had a mean volume of $260 \pm 136 \mathrm{~cm}^{3}$, and the larger coral colonies had a 
152 mean volume of $3706 \pm 1057 \mathrm{~cm}^{3}$. Exosymbionts and other animals were removed from the

153 corals using wooden skewers.

154 Experimental treatments for the small size class (4-6 $\mathrm{mm} \mathrm{CW})$ of crabs were: all

155 symbionts removed $(\mathrm{n}=22)$, small T. serenei $(\mathrm{n}=22)$, and T. punctimanus $(\mathrm{n}=22)$.

156 Experimental treatments for the medium size class $(9-10 \mathrm{~mm} \mathrm{CW})$ only included $T$. serenei and a 157 removal treatment, because $T$. punctimanus does not occur in an equivalent size range. Both 158 experiments were conducted as described below.

$159 \quad$ Forty Drupella with $15-17 \mathrm{~mm}$ aperture lengths were collected from the fore reef, housed 160 in a glass aquarium with a flow-through sea water system and starved for a minimum of 72 hours 161 prior to use in experiments. We placed one $P$. verrucosa colony from each of the three treatments 162 into the center of three assigned tanks. Three Drupella individuals were lined up on the bottom 163 downstream rear edge of each aquarium to ensure the availability of a chemosensory signal from 164 the coral to the snails. Three Drupella were used in each treatment so that a measurable feeding 165 scar would be produced during the experimental period of 19-24 hours. The experiment was 166 repeated each night with a new set of corals and symbionts, with treatments alternating between 167 tanks each day. Drupella were reused after a 72 hour starvation period, and a new cohort of 168 Drupella was collected after ten days and starved as above.

169 After each experiment, the length, width, and height of corals were measured. The size of 170 any feeding scars produced during the experiment was measured. Measurements of the amount of 171 tissue consumed in an irregular three-dimensional branching coral are difficult and contentious.

172 We chose to use proxies of coral volume and feeding scars calculated as the volume of an 173 ellipsoid using the formula: $\mathrm{V}=4 / 3 \pi \mathrm{abc}$, where $\mathrm{a}, \mathrm{b}$, and $\mathrm{c}$ are radii following $\mathrm{M}^{\mathrm{c}} \mathrm{Keon}$ et al.

174 (2012). After each trial the aquaria were scrubbed, rinsed, drained and refilled. 
176 corals; the differences in host size does not allow for direct comparison of the efficacy of small

177 crabs in small corals and larger crabs in larger corals.

\section{Culcita novaeguineae}

Experiments testing defense against Culcita by two medium-sized species of Trapezia

were conducted in flow-through plastic pools of approximately $2,670 \mathrm{~L}$ volume. P. verrucosa

181 were gathered from the back reef environment on the same day of the experiments. Two sets of 182 experiments were conducted with two size classes of corals. Experiments using the larger size183 class of coral colonies (mean volume of $3354 \pm 979 \mathrm{~cm}^{3}$ ) had treatments as follows: pairs of 184 medium-size class $T$. serenei $(\mathrm{n}=20, \mathrm{CW}=9-11 \mathrm{~mm})$, pairs of medium-size class $T$. bidentata 185 (Forskål, 1775) $(\mathrm{n}=17, \mathrm{CW}=9-11 \mathrm{~mm})$, and all symbionts removed $(\mathrm{n}=23)$. The second set of 186 experiments used a smaller size-class of coral (mean volume $519 \pm 175 \mathrm{~cm}^{3}$ ) included pairs of 187 small size-class $T$. serenei in smaller corals $(\mathrm{n}=9, \mathrm{CW}=4-6 \mathrm{~mm})$ and a set with all symbionts

188 removed $(n=8)$. As above, the desired experimental symbiont community was established 189 through manual removal of symbionts and other coral-associated animals. $\mathrm{cm}$ ) in Cook's Bay, Mo'orea, held in large plastic pools with flowing seawater, and were starved

192 for at least 48 hours before experimental use. Corals were positioned in the middle of the plastic 193 pools, and a single Culcita was placed directly on top of each experimental coral at sundown.

194 Predation was evaluated the following morning, after approximately 15 hours. Coral volume and 195 feeding scar dimensions were estimated as noted above.

\section{Acanthaster planci}

Several studies have suggested that Trapezia may be able to repel Acanthaster corallivory

198 (Glynn 1987; Pratchett 2001). These studies have either been observational or conducted as lab 199 experiments. A large outbreak of Acanthaster on Mo'orea beginning in 2008 allowed field 
200

201 largest species of Trapezia. We chose a spur and groove fore reef site off the northern shore of

202 Mo'orea and conducted experiments from October to November of 2008. We manually removed

203 Trapezia flavopunctata from 45 haphazardly selected Pocillopora eydouxi colonies, and selected

204 a second set of 45 coral colonies with pairs of large size-class T. flavopunctata allowed to remain

205 in the coral. The removals were maintained for one month. Other symbiotic species, including

206 fish, arthropods, and smaller species of Trapezia, were left in the coral colonies. Control corals

207 were disturbed in a manner similar to that used to remove T. flavopunctata. Every 48 hours all

208 corals were checked for tissue loss (feeding scars), and measured as described previously.

\section{Results}

210 Drupella cornus

Frequency of predation was significantly higher in corals with symbionts removed (22/22)

212 than in corals containing a small size-class T. serenei pair $(8 / 22$; Fisher's Exact Test, $\mathrm{p}=0.0003)$.

213 Mean tissue loss during predation events was significantly higher in corals with symbionts

214 removed $\left(\mathrm{n}=22,13.9 \mathrm{~cm}^{3}, 8.7 \%\right.$ total coral volume proxy [TCVP]), than in corals containing

215 small T. serenei pairs $\left(\mathrm{n}=8,7.94 \mathrm{~cm}^{3}, 1.3 \%\right.$ TCVP; Student's T-Test $\mathrm{p}=0.003$, Figure 1$)$.

216 Neither predation frequency nor mean tissue loss differed significantly between corals containing

217 the medium size-class of $T$. serenei and the matched set of corals with symbionts removed

218 (predation frequency: Fisher's Exact Test, $\mathrm{p}>0.05$; mean tissue loss: Student's t-test, $\mathrm{p}>0.05$ ).

219 In trials with corals containing T. punctimanus, predation frequency differed significantly

220 between corals with crab pairs present and removed (Fisher's Exact Test, $p=0.0009$ ). Mean

221 tissue loss during predation events was also significantly higher in corals with symbionts

222 removed $\left(\mathrm{n}=20,22.9 \mathrm{~cm}^{3}, 5.7 \%\right.$ of TCVP), than in corals with $T$. punctimanus pairs present $(\mathrm{n}=$

$2239,0.61 \%$ of TCVP; Student's t-test $\mathrm{p}=0.00001$; Fig. 1). 
224

225

226

227

228

229

230

231

232

233

234

235

236

237

238

239

240

241

242 243 on the reef.

244

245

246 247 flavopunctata pairs present (Binomial Proportions Test, $\chi^{2}=18.358, \mathrm{df}=1, \mathrm{p}<0.005$; Electronic

248 Supplemental Material [ESM] 1A). Mean coral tissue loss was 22\% of TCVP in undefended

The differences in defense provided to the coral host by the medium size-class of $T$. serenei and T. bidentata were evaluated using ANOVA. Mean tissue loss differed significantly among treatments: $19 \%$ of TCVP in corals containing T. serenei pairs $(n=5), 37 \%$ of TCVP in corals containing T. bidentata pairs $(\mathrm{n}=10)$, and $49 \%$ of TCVP in corals with symbionts removed $(n=20$; ANOVA: $p<0.01, F=20.77, d f=33$; Fig. 2$)$. There was also a significant difference in tissue loss when the data were analyzed as presence or absence of crab pairs, ignoring species differences (Tukey's HSD, $\mathrm{p}<0.001$ ). Smaller corals with the small size-class of $T$. serenei present $(n=9)$ and removal treatments $(n=8)$ were completely consumed by Culcita, so no statistical test was needed.

\section{Acanthaster planci}

Live coral cover on the fore reef of Mo'orea from 2000-2006 varied from 41-51\%, and was dominated by species of Pocillopora, Porites, and Acropora (Adjeroud et al. 2009). Photos made in 2006 of our immediate study area provided estimated coral cover of about $80 \%$. By September 2008, coral cover had plummeted in northern Mo'orea as a result of a population outbreak of Acanthaster planci. In our study area, total living coral cover had decreased to $3.4 \%$ ( $\mathrm{se}=0.97, \mathrm{n}=45)$ as calculated from quadrat surveys, and most of the coral recorded during the survey were P. eydouxi. Living coral cover changed little by October 2009; with estimated cover at $3.2 \%(\mathrm{se}=0.75, \mathrm{n}=45)$, and Pocillopora eydouxi remained the most abundant coral species attack and tissue loss in hosts. Over the two-week experimental period, 64\% (29/45) of corals with symbionts removed were attacked, compared with $18 \%$ (8/45) of corals with $T$. 
corals and 2\% of TCVP in defended corals (Binomial Proportions Test, $\mathrm{p}<0.005$; ESM 1B).

250 Thirty-four corals from which T. flavopunctata were removed still possessed a complement of

251 other Trapezia species and other symbiotic taxa. We compared attack frequency between $P$.

252 eydouxi with T. flavopunctata and smaller-size Trapezia species present (10 attacks/33 corals), to

253 corals from which $T$. flavopunctata had been removed, but with other symbionts left alone (24

254 attacks/34 corals). Corals with $T$. flavopunctata removed suffered attack by Acanthaster more

255 frequently (Binomial Proportions Test, $\chi^{2}=9.3214, \mathrm{df}=1, \mathrm{p}=0.0022$ ).

256 Discussion

257 Efficacy of defense against corallivores differed among Trapezia species as well as among 258 size classes. Small $(\mathrm{CW}=4-6 \mathrm{~mm})$ T. punctimanus and T. serenei were comparably effective in 259 defending against Drupella, while larger $(\mathrm{CW}=9-10 \mathrm{~mm})$ T. serenei were ineffective. However, 260 large $(\mathrm{CW}=9-11 \mathrm{~mm}) T$. serenei were effective in defending against Culcita, while small $T$.

261 serenei $(\mathrm{CW}=4-6 \mathrm{~mm})$ were not. Furthermore, large $(\mathrm{CW}=9-11 \mathrm{~mm})$ T. serenei were 262 significantly more effective host defenders than comparably sized T. bidentata against Culcita 263 predation, suggesting that specific identity, as well as size plays a role in the level of protective 264 service provided to the coral host. Finally, during the Acanthaster outbreak only corals hosting 265 the largest Trapezia species, i.e., T. flavopunctata or T. rufopunctata, survived. Smaller-size 266 Trapezia species were unable to protect their hosts against the largest of the three predators, and 267 the corals were quickly attacked when $T$. flavopunctata were removed.

268 These results suggest ecological complementarity, as well as a hierarchy of defensive 269 effectiveness among different species and sizes of Trapezia. Small crabs effectively defend their 270 hosts against the small predator Drupella, but fail against larger predators such as Culcita: small 271 Pocillopora were always consumed entirely by Culcita, regardless of the presence or absence of 272 small Trapezia. The crabs flee the coral, or are consumed along with the host. 
274 species, but they do not defend against Drupella or Acanthaster. The largest crabs actively defend 275 against Acanthaster, but their efficacy against the other coral predators remains untested. Thus, 276 barring the untested possibility of negative interactions, a coral harboring all of these symbionts 277 may be defended against all three corallivores, while a coral with a lesser complement of 278 Trapezia species may remain vulnerable to some predators. An additional aspect of this within 279 guild complementarity, or 'species stacking', is that several species may create additional 280 synergistic defensive effects even against the same coral predator ( $\mathrm{M}^{\mathrm{c}} \mathrm{Keon}$ et al. 2012). These results also suggest that the characteristics of the mutualism between Trapezia and 282 Pocillopora may shift as the resident crabs and coral hosts increase in size. Because the feeding 283 scars of the corals without symbionts in the small T. serenei and T. punctimanus experiments 284 were nearly the same size as the feeding scars in both groups of the large $T$. serenei experiments, 285 it may be possible that the threat to smaller crabs and their correspondingly smaller hosts by 286 Drupella predation is proportionally greater. This proportional response may explain why larger 287 crabs did not respond as effectively as the smaller crabs to Drupella. Glynn (1980) suggested 288 that another small species of Trapezia, T. formosa may not play a role in defending their host 289 corals against Acanthaster. However, we have shown that smaller species of Trapezia previously

290 thought to be ineffective guards, because they were only tested against Acanthaster, can play 291 important defensive roles against other corallivores. The efficacy of protection provided by two species of Trapezia (T. serenei and T.

293 bidentata) against Culcita differed under controlled conditions. Both significantly reduced the 294 frequency of attack and volume of tissue consumed by Culcita, but T. serenei was more effective.

295 This may be because T. serenei is more common in the back reef habitat where Culcita

296 populations are most dense, while $T$. bidentata is more common in fore reef environments where 297 Culcita is less frequently encountered in Mo'orea. 
Both attack rate and the amount of coral tissue consumed by Acanthaster were

299 significantly reduced by the presence of the largest species in the system, Trapezia flavopunctata.

300 Acanthaster preyed upon P. eydouxi when Trapezia flavopunctata were removed. Species of

301 Pocillopora that do not host T. flavopunctata were completely consumed by Acanthaster in the

302 reef area studied, despite the frequency of occupancy of other Trapezia spp. exceeding 90\%

303 (Stewart et al. 2006; $\mathrm{M}^{\mathrm{c}}$ Keon et al. 2012).

304 The protective impact of T. flavopunctata appeared to extend beyond the host coral,

305 providing protection for a microcommunity of reef corals in the vicinity of their host. In a survey

306 conducted at the same time as these field trials, 61 colonies of 13 other reef coral species,

307 eliminated from the reef in all other areas by Acanthaster, were found under and immediately

308 beside of 90 P. eydouxi-symbiont communities (Figure 3). No living corals were found in similar

309 positions around 90 recently dead P. eydouxi of similar size in the same area. Indirect,

310 associational defense has previously been documented among reef corals in the same location

311 (Kayal et al. 2010). Protection provided by the presence of the largest species of Trapezia is

312 another potential mechanism for the survival of reef corals in Acanthaster outbreaks.

313 The results of these experiments raise many questions about the Trapezia-Pocillopora

314 mutualism. Glynn (1980) demonstrated that Trapezia respond aggressively to chemical signals

315 produced by Acanthaster, but whether Trapezia are able to detect and respond to chemical signals

316 produced by other corallivores such as Drupella remains unknown.

317 During an analysis of coral population dynamics in Australia, Hughes and Connell (1987)

318 found that $39 \%$ of Pocillopora damicornis measuring less than $10 \mathrm{~cm}^{2}$ died over the course of

319 one year, while only $8 \%$ of $P$. damicornis measuring between 10 and $50 \mathrm{~cm}^{2}$ suffered the same

320 fate. While differential mortality is expected with changes in colony size, impacts of mutualists

321 on different sizes of corals should be examined. The frequency of occurrence of Trapezia in

322 medium-sized Pocillopora colonies is well documented (Huber and Coles 1985; Sin and Lee 
323 2000; Stewart et al. 2006) but our understanding of the occurrence of Trapezia in very small

324 corals is limited. In recent work by Stewart et al. (2013), growth of small Pocillopora was

325 positively impacted by the presence of recently recruited Trapezia serenei through the removal of

326 sediment. Similar work on the ontogeny of defense from corallivores is needed.

327 While the largest crab species provide the greatest defensive efficacy against Acanthaster,

328 the energy expenditure of the host coral to maintain the symbiosis may also be costly. As the

329 frequency of Acanthaster outbreaks on Mo'orea has been on an approximately 30-year cycle

330 (Faurea 1989) attacks by seastars may be relatively rare events in the life of a coral. Removal of

331 sediment and deterrence of smaller corallivores, such as Drupella, may be more common needs

332 for coral, even if the size of their impact on a colony may not be as severe as that resulting from

333 Acanthaster attack. The beneficial role of different symbiont species and size classes to this

334 spectrum of impact may be sufficient to increase the fitness of corals that maintain the nutritive

335 benefits that are provided to the crabs (Stimson 1990).

336 The experiments we conducted suggest that functional diversity exists in the Pocillopora-

337 Trapezia mutualism at a species level. But we must acknowledge the limitations of our study:

338 we were unable to use all species of Trapezia present in the system, in a single size and species of

339 Pocillopora. Variation within the mutualism was demonstrated to impact coral host survival

340 across the size ranges of host and symbiont. Interactions between the species and size classes are

341 likely an integral part of the mechanisms that promote the existence of the Pocillopora-Trapezia

342 mutualism, but have yet to be explored in depth. Variation in the services provided by mutualists

343 has been recorded in a wide variety of systems (Addicott 1986; Bronstein and Hossaert-McKey

344 1996; Del-Claro and Oliveira 2000). Therefore, the assumptions underlying construction of

345 functional groups may be weaker than generally noted in the literature, and functional groups of

346 questionable utility in understanding diverse mutualist systems. 
347 Our studies suggest that measuring a diversity of response variables is important in 348 assessing the level of functional diversity present in a system. Our results demonstrate the 349 importance of the Trapezia-Pocillopora mutualism in response to corallivory, including an 350 outbreak of Acanthaster. A diverse symbiont fauna may provide individual corals with greater

351 protection from a suite of predators. Moreover, these benefits may cascade beyond the individual 352 coral colony and have far-reaching impacts on the reef, by altering the demography of small 353 corals, structuring the surviving communities of corals and offering associational defenses and 354 refuge to nearby corals during catastrophic predator outbreaks. 
355

356 We are grateful to Gustav Paulay, François Michonneau, Mike Gil, and Nat Seavy for their 357 suggestions and comments on the manuscript. We would also like to thank the staff of UC

358 Berkeley's Richard B. Gump South Pacific Research Station. This project was funded by an 359 Alumni Fellowship from University of Florida to C.S. M'Keon, and the BIOCODE Mo'orea 360 project to G. Paulay. Logistical support was provided by the BIOCODE Mo'orea Project.

\section{References}

362 363

Acevedo R, Morelock J, Olivieri R (1989) Modification of coral reef zonation by terrigenous sediment stress. Palaios 4:92-100

Adams J, Edwards AJ, Emberton H (1985) Sexual size dimorphism and assortative mating in the obligate coral commensal Trapezia ferruginea Latreille (Decapoda, Xanthidae). Crustaceana 48:188-194

Addicott J (1986) Variation in the costs and benefits of mutualism: the interaction between yuccas and yucca moths. Oecologia 93:512-517

Adjeroud M, Michonneau F, Edmunds P, Chancerelle Y, Lison de Loma T, Penin L, Thibaut L, Vidal-Dupiol J, Salvat B, Galzin R (2009) Recurrent disturbances, recovery trajectories, and resilience of coral assemblages on a South Central Pacific reef. Coral Reefs 28:775780

Barshis DJ, Stillman JH, Gates RD, Toonen RJ, Smith LW, Birkeland C (2010) Protein expression and genetic structure of the coral Porites lobata in an environmentally extreme Samoan back reef: Does host genotype limit phenotypic plasticity? Mol Ecol 19:17051720

Baskett ML, Gaines SD, Nisbet RM (2009) Symbiont diversity may help coral reefs survive moderate climate change. Ecol Appl 19:3-17 
379 Birkeland C (1989) The Faustian traits of the Crown-of-thorns starfish. Am Sci 77:154-163

380 Bracken MES, Gonzalez-Dorantes CA, Stachowicz JJ (2007) Whole-community mutualism:

381 Associated invertebrates facilitate a dominant habitat-forming seaweed. Ecology 88:2211-

$382 \quad 2219$

383 Bronstein JL, Hossaert-McKey M (1996) Variation in reproductive success within a subtropical 384 fig/pollinator mutualism. J Biogeogr 23:433-446

385 Castro P (1997) Trapeziid crabs (Brachyura: Xanthoidea: Trapeziidae) of French Polyneisa. In:

386 Richer de Forges B, ed. Les fonds meubles des lagons de Nouvelle-Caldéonie

387 (Sédimentologie, Benthos). Études \& Thèses, volume 3, Paris, Orstom, 109-139.

388 Castro P, Ng PKL, Ahyong ST (2004) Phylogeny and systematics of the Trapeziidae Miers, 1886

389 (Crustacea: Brachyura), with the description of a new family. Zootaxa 643:1-70

390 Chalcraft DR, Resetarits WJ (2003) Predator identity and ecological impacts: Functional

391 redundancy or functional diversity? Ecology 84:2407-2418

392 Combosch, DJ, Guzman HM, Schuhmacher H, Vollmer SV (2008) Interspecific hybridization and 393 restricted trans-Pacific gene flow in the tropical Eastern Pacific Pocillopora. Molecular $394 \quad$ Ecology 17:1304-1312

395 Correa AMS, Baker AC (2009) Understanding diversity in coral-algal symbiosis: a cluster-based 396 approach to interpreting fine-scale genetic variation in the genus Symbiodinium. Coral $397 \quad$ Reefs 28:81-93

398 Del-Claro K, Oliveira P (2000) Conditional outcomes in a neotropical treehopper-ant association: 399 temporal and species-specific variation in ant protection and homopteran fecundity.

$400 \quad$ Oecologia 124:156-165

401 Faurea G (1989) Degradation of coral reefs at Moorea Island (French Polynesia) by Acanthaster $402 \quad$ planci. J Coast Res 5:295-305 
403 Glynn P (1976) Some physical and biological determinants of coral community structure in the $404 \quad$ Eastern Pacific. Ecol Monogr 46:431-456

405 Glynn P (1980) Defense by symbiotic crustacea of host corals elicited by chemical cues from $406 \quad$ predator. Oecologia 47:287-290

407 Glynn P (1987) Some ecological consequences of coral-crustacean guard mutualisms in the $408 \quad$ Indian and Pacific Oceans. Symbiosis 4:301-324

409 Glynn P, Krupp D (1986) Feeding biology of a Hawaiian sea star corallivore, Culcita $410 \quad$ novaeguineae Muller \& Troschel. J Exp Mar Biol Ecol 96:75-96

411 Harris PM (1995) Are autecologically similar species also functionally similar - a test in pond 412 communities. Ecology 76:544-552

413 Howe HF (1984) Constraints on the evolution of mutualisms. Am Nat 116:441-448

414 Hubbell SP (2005) Neutral theory in community ecology and the hypothesis of functional 415 equivalence. Funct Ecol 19:166-172

416 Huber ME, Coles SL (1985) Resource utilization and competition among the five Hawaiian 417 species of Trapezia (Crustacea, Brachyura). Mar Ecol Prog Ser 30:21-31

418 Hughes TP, Connell JH (1987) Population dynamics based on size or age? A reef coral analysis. 419 Am Nat 129:818-829

420 Kayal M, Lenihan HS, Pau C, Penin L, Adjeroud M (2010) Associational refuges among corals 421 mediate impacts of a crown-of-thorns starfish Acanthaster planci outbreak. Coral Reefs 422 $30: 827-837$

423 Lasker HR (1980) Sediment rejection by reef corals - the roles of behavior and morphology in 424 Montastrea cavernosa (Linnaeus). J Exp Mar Biol Ecol 47:77-87

425 Leibold MA, McPeek MA (2006) Coexistence of the niche and neutral perspectives in $426 \quad$ community ecology. Ecology 87:1399-1410

427 Loreau M (2004) Does functional redundancy exist? Oikos 104(3):606-611 
428 Loreau M, Naeem S, Inchausti P (eds) (2002) Biodiversity and ecosystem functioning: synthesis 429 and perspectives. Oxford University Press

430 M$^{\mathrm{c}}$ Keon CS (2010) Diversity in a tropical marine mutualism. Ph.D. thesis, University of Florida, $431 \quad \mathrm{p} 123$

432 MKeon CS, Stier AC, Boyer S, Bolker BM (2012) Multiple defender effects: Synergistic coral 433 defense by mutualist crustaceans. Oecologia 169:1095-1103

434 Menge BA, Sutherland JP (1987) Community regulation - variation in disturbance, competition, 435 and predation in relation to environmental-stress and recruitment. Am Nat 130:730-757

436 Meunier L, Dalecky A, Berticat C, Gaume L, McKey D (1999) Worker size variation and the 437 evolution of an ant-plant mutualism: comparative morphometrics of workers of two closely related plant-ants, Petalomyrmex phylax and Aphomomyrmex afer (Formicinae). Insectes Soc 46:171-178

Morris WF, Hufbauer RA, Agrawal AA, Bever JD, Borowicz VA, Gilbert GS, Maron JL, Mitchell CE, Parker IM, Power AG, Torchin ME, Vazquez DP (2007) Direct and interactive effects of enemies and mutualists on plant performance: A meta-analysis. Ecology 88:1021-1029

Odinetz MO (1983) Ecologie et structure des peuplements de crustacés décapodes associés aux coraux du genre Pocillopora en Polynésie française et en Micronésie (Guam). Ph.D. thesis, Université Pierre et Marie Curie

Pearson RG, Endean R (1969) A preliminary study of the coral predator Acanthaster planci (L.) (Asteroidea) on the Great Barrier Reef. Fisheries Notes, Queensland Dept Harbours and Marine 3:27-55

449 Pratchett M (2001) Influence of coral symbionts on feeding preferences of crown-of-thorns starfish Acanthaster planci in the western Pacific. Mar Ecol Prog Ser 111-119

451 Pratchett M (2007) Feeding preferences of Acanthaster planci (Echinodermata: Asteroidea) under 452 controlled conditions of food availability. Pac Sci 113-120 
453 Pratchett MS, Schenk TJ, Baine M, Syms C, Baird AH (2009) Selective coral mortality

454 associated with outbreaks of Acanthaster planci L. in Bootless Bay, Papua New Guinea.

$455 \quad$ Mar Environ Res 67:230-236

456 R Development Core Team. 2006. R: A language and environment for statistical computing. R

457 Foundation for Statistical Computing, Vienna, Austria.

458 Resetarits WJ, Chalcraft DR (2007) Functional diversity within a morphologically conservative

459 genus of predators: implications for functional equivalence and redundancy in ecological $460 \quad$ communities. Funct Ecol 21:793-804

461 Schemske D, Horvitz C (1984) Variation among floral visitors in pollination ability: a

462 precondition for mutualism specialization. Science 225:519-521

463 Sin TM, Lee AC (2000) Host specialisation in trapeziid crabs: Consequences for rarity at local $464 \quad$ scales. Proc $9^{\text {th }}$ Int Coral Reef Symp 1:533-536

465 Smith LW, Barshis D, Birkeland C (2007) Phenotypic plasticity for skeletal growth, density and 466 calcification of Porites lobata in response to habitat type. Coral Reefs 26:559-567

467 Stachowicz JJ, Whitlatch RB (2005) Multiple mutualists provide complementary benefits to their $468 \quad$ seaweed host. Ecology 86:2418-2427

469 Stachowicz JJ, Graham M, Bracken MES, Szoboszlai AI (2008) Diversity enhances cover and $470 \quad$ stability of seaweed assemblages: The role of heterogeneity and time. Ecology 89:3008$471 \quad 3019$

472 Staffordsmith MG, Ormond RFG (1992) Sediment-rejection mechanisms of 42 species of 473 Australian scleractinian corals. Aust J Mar Freshw Res 43:683-705

474 Stewart HL, Holbrook SJ, Schmitt RJ, Brooks AJ (2006) Symbiotic crabs maintain coral health $475 \quad$ by clearing sediments. Coral Reefs 25:609-615 
476 Stewart HL, Price NN, Holbrook SJ, Schmitt RJ, Brooks AJ (2013) Determinants of the onset

477 and strength of mutualistic interactions between branching corals and associate crabs.

$478 \quad$ Marine Ecology Progress Series 493:155-163

479 Stier A, MKeon CS, Osenberg CW, Shima JS (2010) Guard crabs alleviate deleterious effects of $480 \quad$ vermetid snails on a branching coral. Coral Reefs 29:1019-1022

481 Stimson J (1990) Stimulation of fat-body production in the polyps of the coral Pocillopora 482 damicornis by the presence of mutualistic crabs of the genus Trapezia. Mar Biol 106:211$483 \quad 218$

484 Turner SJ (1994) The biology and population outbreaks of the corallivorous gastropod Drupella 485 on Indo-Pacific reefs. Oceanogr Mar Biol Annu Rev 32:461-530

486 Veron JEN (2000) Corals of the World. Australian Institute of Marine Science, Townsville, $487 \quad$ Australia

488 Veron JEN, Pichon M (1976) Scleractinia of Eastern Australia. Australian Government 489 Publishing Service, Canberra, Australia

490 Vogler C, Benzie J, Lessios H, Barber P, Worheide G (2008) A threat to coral reefs multiplied?

$491 \quad$ Four species of crown-of-thorns starfish. Biol Lett 4:696-699 


\section{Figure 1}

Percentage of coral tissue volume proxy consumed by Drupella cornus in corals hosting the small size-class of Trapezia serenei and Trapezia punctimanus. Letters indicate post-hoc statistically significant differences between groups 
$40-$

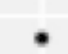

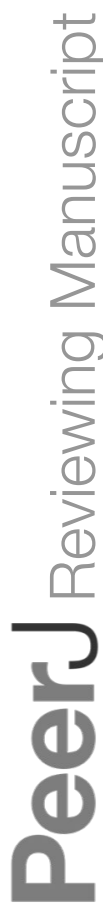

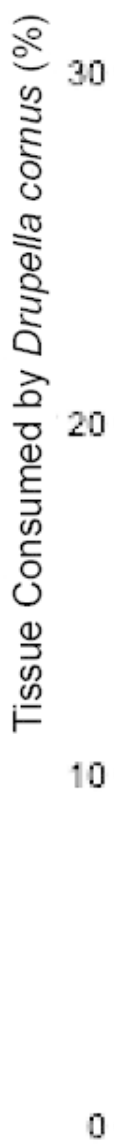

A
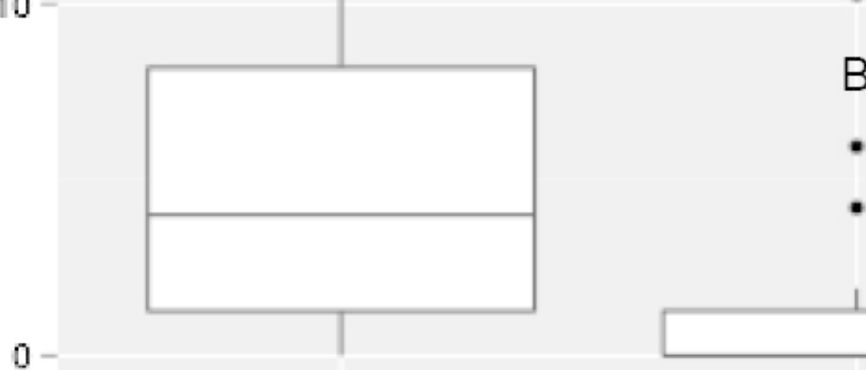

B

B

Crabs removed

Trapezia serenei

Trapezia punctimanus 


\section{Figure 2}

Percentage of coral tissue volume proxy consumed by Culcita novaeguineae in corals hosting the large size-class of Trapezia bidentata and Trapezia serenei. Letters indicate post-hoc statistically significant differences between groups. 


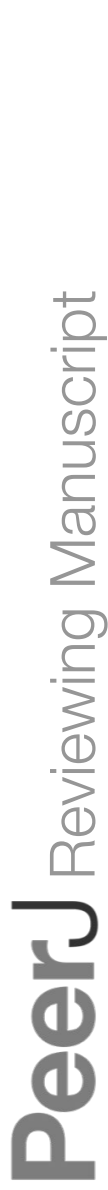

70

ㅇํㅇ

(1) $60=$

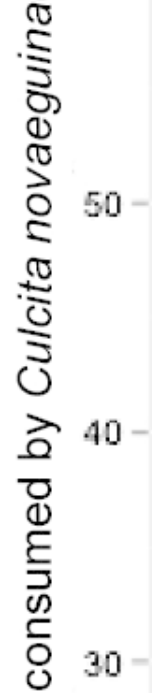

ป

怘

$i$

20

$10-$

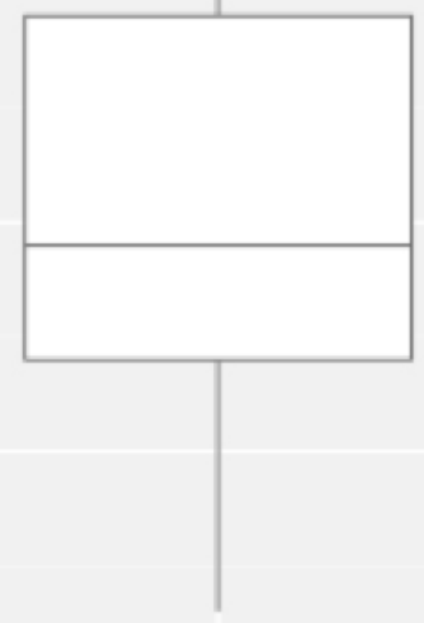

A

B

C
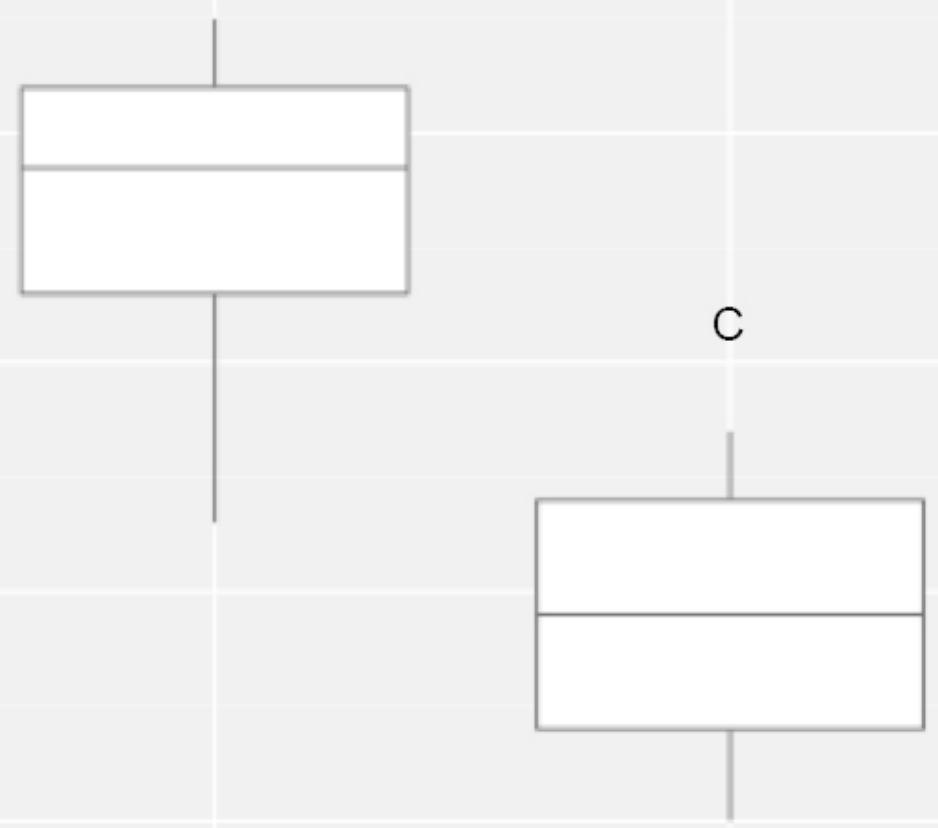

Crabs removed

Trapezia bidentata

Trapezia serenei 


\section{Figure 3}

Examples of corals sheltered by living Pocillopora eydouxi and Trapezia flavopunctata.

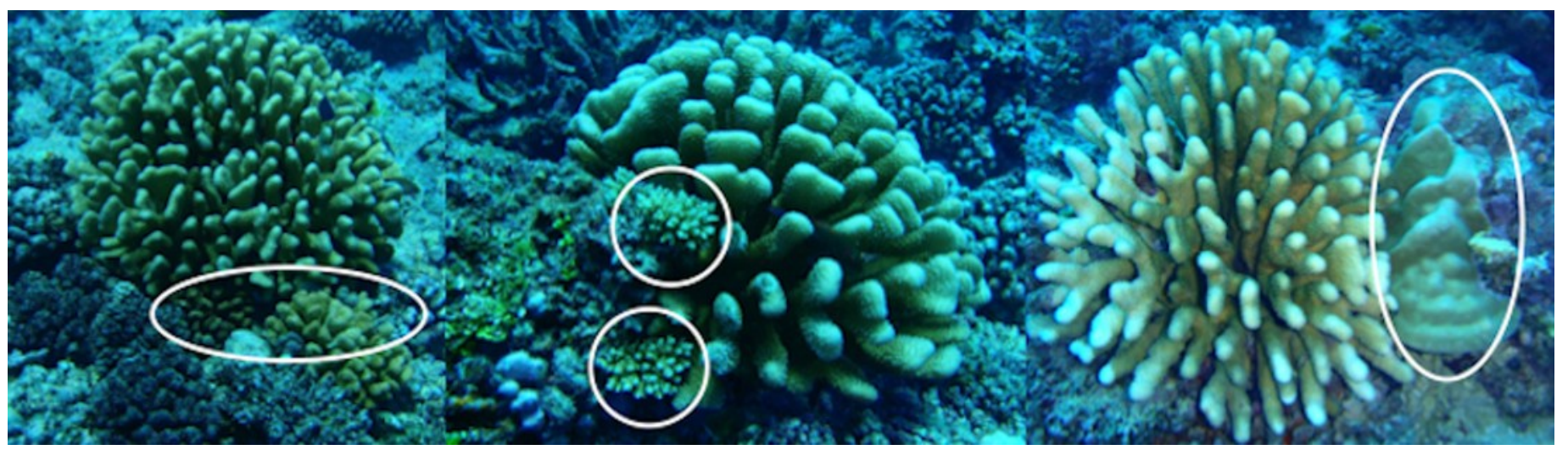

